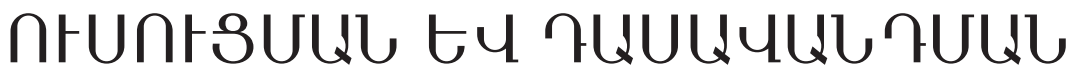 \\ UtaกาคนL
}

\author{
ВИОЛЕТТА ГРИГОРЯН \\ Доцент кафедры русского языка и профессиональной \\ коммуникации Российско-Армянского (Славянского) уни- \\ верситета, кандидат педагогических наук
}

\section{АКТУАЛЬНОСТЬ ОБУЧЕНИЯ НА ФИЛОЛОГИЧЕСКИХ ФАКУЛЬТЕТАХ ПРАВИЛАМ ЛИНГВИСТИЧЕСКОГО АНАЛИЗА ТЕКСТА}

В настоящее время на филологических факультетах вузов в системе профессиональной ориентации процесса обучения русскому языку особую актуальность приобретает задача обучению правилам анализа текста (научного, художественного). Несмотря на многоаспектность существующих исследований текста, есть все основания для организации полученных наблюдений в некоторую систему, дающую представление о строении русского монологического текста. Положив эту систему в основу, можно разработать комплекс заданий для обучения научному стилю речи по профилю будущей специальности студентов.

Ключевые слова и словосочетания: анализ текста (научного, художественного), филологический факультет, связный монологический текст, структура текста, содержание текста.

В настоящее время на филологических факультетах вузов в системе профессиональной ориентации учебного процесса особую актуальность приобретает задача обучению правилам анализа текста (научного, художественного).

В.А. Звегинцев справедливо называет сферу описания связного текста “заоблачной языковой областью” [1]; В. Дресслер отмечает, что не так давно интерес к супрасинтаксису “...большей частью исчерпывался разного рода дакларациями и неопределенными указаниями [2, с. 112].

Чтобы избежать возможных оценок такого рода, мы берем за основу рассмотрения текста (с учетом методического аспекта) формальные (а потому вполне ощутимые и доступные непосредственному восприятию) критерии, хотя, конечно, в основе структуры текста лежат смысловые отношения. Смысл полностью игнорировать нельзя, нет смысла - нет текста. Но если в начале предложения употреблен сочинительный союз, выражающий систематичность предложения, то смысловая зависимость предложения от контекста получает вполне определенную языковую конкретизацию: ведь если смысл предложения этого союза не требовал, союз бы и не появился.

Мы разделяем мнение В. Дресслера, считающего, что “...построение систематической лингвистики текста на семантических основаниях было бы, пожалуй, преждевременным" [3, с. 112]. В практике преподавания русского языка как иностранного необходимо ограниченное количество по возможности четко сформулированных правил, ру- 
ководствуясь которыми иностранный учащийся может воспринимать или строить высказывание, включающее несколько предложений.

Такие правила должны быть получены в ходе учебного процесса на материале, дающем широкие возможности для переноса сформированных на нем навыков и умений в различные сферы использования языка.

Что же мы понимаем под текстом? Текст - это письменное по форме речевое произведение, принадлежащее одному участнику коммуникации, законченное и правильно оформленное [4, с. 61].

Опора на письменные источники, несомненно, имеет свои минусы [10], но тем не менее в практике лингвистического анализа текста ощутимые результаты получены именно при обращении к письменным, а не спонтанно созданным текстам, появлению которых сопутствовал процесс предварительного обдумывания.

“Выбор письменного текста в качестве материала для анализа обусловлен тем, что письменная речь - это наиболее адекватная форма реализации языковой системы, так как в устной речи в силу того, что она ситуативна, допустимы различного рода отклонения от существующих норм языка...” [5, с. 8]. Более того, в процессе профессиональной ориентации студентов мы опираемся именно на письменные тексты.

В данном исследовании источником анализа являются тексты художественной литературы, хотя можно было бы привлечь для исследования любой текст, независимо от его социальных и предметных констант [6, с.46], поскольку язык един во всех его проявлениях. Какую бы сферу использования языка мы не рассматривали, мы не сможем обнаружить качественного различия между связями предложений, допустим, в тексте художественной литературы и научном тексте.

Связь предложений и в том, и в другом тексте будет обеспечиваться сочинительными союзами, местоимениями определенных разрядов и т.п. Количество этих средств связи в различных стилях, естественно, не может не быть различным. Принципиально типы связей предложений между собой во всех стилях будут одинаковы.

В процессе анализа текстообразующих закономерностей мы не будет отказываться от тех бесспорно ценных наблюдений, которые накопились за длительное время. Необходимо только привести их в систему, подвергнув переосмыслению взгляд на предложение как непременный элемент группы, и на единицы текста как на хаотично располагаемые.

Последовательно реализуемая идея уровневого строения языковой системы предполагает высший уровень - уровень текста. Признаки этого уровня пока не получили конкретизации. Здесь возможны два взаимоисключающих вывода:

- Если не найдено определенных параметров, хорактеризующих уровень текста, то этого уровня не существует, и идея уровневого строения заканчивает свое воплощение на уровне предложения;

- Признаки уровня есть, но они еще не обнаружены.

В.А. Звегинцев, говоря о лингвистических уровнях, отмечает, что сторонники теории уровней часто - и не всегда отдавая себе в этом отчет - имеют в виду не столько теории строения языка [7, с. 43], сколько теорию описания языка. Действительно, уровневое строение языка весьма условно, и эта условность подтверждается или опровергается по 
мере накопления и осмысления исследованного материала.

Описание же языка с использованием понятия уровня преследует цели создания некоего конструкта, поиски которого при рассмотрении конкретных языковых явлений - следствие использования чрезмерно усложнившейся в последнее время лингвистической терминологии.

Мы не отказываемся от понятия “уровень текста”, но не расцениваем этот уровень как занимающий самое высокое место в иерархии языковых единиц. Иерархическое осмысление этого понятия вынуждает исследователя рассматривать в качестве условия существования предложения обязательное вхождение в группу.

Такая трактовка предложения идет вразрез с нашими прикладными задачами, не учитывать которые - значит создавать ненаправленную классификацию, классификацию без адресата. В нашем случае адресатом является студенческая аудитория, поэтому прикладная направленность исследования становится очевидной.

Недостаточная результативность некоторых исследований, направленных на выявление закономерностей в построении групп предложений, привела к таким заключениям: “... на самом деле “синтаксическое единство” - явление речевое, а не структурно-типологическое, поэтому оно не имеет определенности, то есть стабильной структуры, как другие языковые единицы...”Синтаксическое единство” является единицей речи “[8, с. 39-40].

Неудачи при поисках стабильности в построении группы предложений мы объясняем опять-таки приверженностью ряда лингвистов индуктивному процес- су исследования. Если считать закономерностью организации группы предложений стопроцентную проявляемость во всех наблюдаемых языковых феноменах определенного ранга, то можно по праву отрицать стабильность в структуре высказывания, состоящего из нескольких предложений.

Но если под закономерностью организации группы предложений понимать характеристики, единые не для максимального, а для преобладающего количества случаев, то можно предполагать, что поиски увенчаются некоторым успехом. При этом отношение к языковым фактам должно быть достаточно осторожным и в некотором смысле недоверчивым: если в поле зрения в какой-то момент оказываются явления, не подтверждающие ранее обнаруженную характеристику, то вывод может быть отрицательным - “закономерностей нет”- или конструктивным - “рассматриваемые случаи иллюстрируют исключение из правила”.

Если некоторые характеристики анализируемой группы предложений мы расцениваем как обоснование для выделения инварианта, то мы уже не вправе относить группу предложений к речевым и только речевым явлениям, считать ее только функциональной единицей. В таком случае мы не ошибемся, если будем говорить о группе предложений как о лингвистической единице, понимать группу предложений не только как нечто наблюдаемое, но и как нечто представляемое, относящееся не к языку, а к описанию языка.

Значимость отнесенности предложения к какому-либо речевому типу - повествованию, описанию или рассуждению - при определении зависи- 
мости/независимости предложения от контекста не вызывает сомнений. В работах многих отечественных и зарубежных лингвистив различаются тексты, формулирующие точку зрения говорящего о поступке и точку зрения совершившего поступок [9, с.15]. Различение отнесенности предложений к типам речи свидетельствует о стремлении исследователей видеть предмет рассмотрения монолитным, приближающимся к речевому произведению, исходящему только от одного производителя речи.

Нашей задачей является “поиск отношений между высказываниями [10, с. 13] “поиск общих закономерностей, а не анализ отдельных употреблений”[11, с.9], поиск правил “соединения предложений на синтагматической плоскости”[12, с. 203]. Именно этот аспект с прагматической точки зрения должен заинтересовать методистов.

В последние годы предприняты интересные попытки изучения правил построения текста с помощью понятия пресуппозиции. Пресуппозиционная основа анализа текста - признак особой значимости левого контекста”[13]. Но применителньо к принципам, положенным в основу данной статьи, понятие пресуппозиции не используется, поскольку анализ текста строится на основах синтаксической формы.

Кроме того, применение к анализу понятия пресуппозиции - еще одно косвенное подтверждение несамостоятельности предложения. В.А. Звегинцев пришет, что “мы имеем все основания определить псевдопредложение (то есть самостоятельное предложение, независимое от окружения - В.Г.) как абстрактную комплексную модель речевой деятельности [14, с. 128]. Текст типа Вера хорошо говорила по-польски. Она хромала на правую ногу. В.А.Звегинцев связным в полном смысле этого слова не считает, отмечая, что здесь имеет место только формальная связь.

Не соглашаясь с такой оценкой приведенного отрезка текса, позволим себе заметиь, что дискурс, не имеющий выраженных форм, никак не может считаться речевым явлением, то есть явлением, дающим основания хотя бы для наблюдения. Это понятие даже не лингвистическое, поскольку конструкт должен являться следствием типизации преобладающего количества реальных речевых форм.

Но эти заявления слишком абстрактны, чтобы служить доказательством. Нам гораздо ближе в этом отношении мысль Х.Изенберга о том, чтотеория текста должна объяснить, “...в каких ситуациях предложение в языковом контекстеможет рассматриваться как возможная часть текста и в каких - нет”[15, с. 54]. Принять это положение мы считаем более целесообразным.

Правомерность реализации лингвистических построений как таковых подробно анализируется в работе И.П. Распопова [16]. Очевидно, не случайно автор, занимаясь проблемами синтаксиса, пришел к необходимости изложить принципы, которые должны быть положены в основу построения, представляющую теоретическую базу описания языковых явлений.

Любая концепция, чтобы иметь право на существование, должна согласовываться с фактами, лежащими в ее основе [17, с. 14]. Интерпретация этих фактов не должна быть противоречивой [18, 20].

Под фактами мы понимаем как собственно языковые феномены, так и ряд 
наблюдений и обобщений, сделанных лингвистиами. В этом смысле мы должны уделить внимание рассмотрению места отдельного предложения в языковой системе. Вычленение групп предложений должно быть разумно ограничено. Не следует стремиться относить любое предложение к некоторому единству.Желательно ориентироваться на языковые показатели, сигнализирующие о зависимости предложения от контекста или, наоборот, о его известной изолированности от окружения.

Если средства создания единства предложений относятся к компетенции стилистики (структурный параллелизм, видо-временное согласование, перифраза), считать их релевантыми в первую очередь не следует. Это будет соблюдением и принципа оптимальности. Согласно данному принципу, “... к описанию и объяснению изучаемых объектов следует подходить наиболее простым, наиболее экономным способом, принимая во внимание лишь те их признаки и свойства, которые считаются для них в определенном отношении существенными"[19, с. 24].

Следует иметь в виду, “... что никакая наука не в состоянии описать и объяснить “поведение” эмпирически фиксируемых индивидуальных феноменов с принципиально бесконечным и постоянно изменяющимся числом свойств”[20, с. 14]. Ориентируясь на это положение, мы выделяем текстовую категорию последовательности - понятие в достаточной мере абстрактное, аппроксимированное, но позволяющее систематизировать огромное, с трудом поддающееся общему исчислению проявление функционирования схемы предложения в его речевых вариантах.
Предложения простые, сложносочиненные и бессоюзные, по нашим наблюдениям, могут занимать в тексте обособленную позицию, а могут и входить в состав группы. Парцеллированную чать предложения мы отдельным предложением не считаем, то есть не сохраняем за ней права выступать обособленно. Под группой же предложений мы понимаем единство, состоящее как минимум из двух предложений (каждое из которых может быть простым, сложносочиненным, сложноподчиненным, бессоюзным).

Признаками, в соответствии с которыми определяется несамостоятельность предложения, являются общеизвестные показатели синсематичности предложения, выявляемые в нем сравнения с левым и правым контекстом.

Мы считаем методически неверным часто встречающееся в ряде работ заявление типа: это предложение связано с другими предложениями, потому что оно зависит от них. К тому же ретроспективное видение текста возможно далеко не во всех условиях коммуникации. Поэтому ориентацию на левый (гораздо реже - на правый) контекст мы допускаем в том случае, когда установлена - на основании только языковых характеристик -зависимость/независимоть предложения от окружающих его единиц.

Условия установления принадлежности предложений к определенному речевому типу включается нами как дополнительное на основании той заинтересованности, которую многие ученые проявляют к функционально-смысловому членению речи (О.А. Нечаева, Г.Я. Солганик и др.)

Оговорим, что наша интерпретация фактов принадлежности предложения 
к какому-либо речевому типу несколько иная: прежде всего она подчинена идее связанности текста, выраженной языковыми характеристиками.

Отнесенность предложения к определенному речевому типу выявляется нами также без сравнения с левым и правым контекстом.

Мы не утверждаем, что предлагаемая классификация единиц является универсальной, единственно возможной и отвергающей все другие концепции. Как справедливо замечает Г.В. Колшанский, “...текст может быть структурирован по различным признакам, которые вряд ли способны де- формировать основные грамматические признаки высказывания"[17, с. 87].

Несмотря на многоаспектность и порой кажущуюся несовместимость существующих исследований текста, есть все основания для организации полученных наблюдений в некоторую непротиворечивую систему, дающую представление о строении связного русского монологического текста. Положив эту систему в основу, можно разработать комплекс заданий для обучения научному стилю речи по профилю будущей специальности студентов. Дата представления статьи:09.12.20132.

\section{ЛИТЕРАТУРА}

1. Звегинцев В.А. Предложение и его отношение к языку и речи. М., 1976.

2. Дресслер В. Синтаксис текста. - В кн.: Новое в зарубежной лингвистике; Лингвистика текста. М., 1978.

3. Там же.

4. Николаева Т.М. Лингвистика текста: Современное состояние и перспективы. - В кн.: Новое в зарубежной лингвистике; Лингвистика текста. М., 1978.

5. Азизян С.А. Методика обучения видо-временным формам английского глагола для употребления в устном монологическом высказывании. Автореф. дис. на соиск. учен. степени канд. пед. наук. М., 1978.

6. Изенберг Х. О предмете лингвистической теории текста. - В кн.: Новое в зарубежной лингвистике; Лингвистика текста. М., 1978.

7. Звегинцев В.А. Предложение и его отношение к языку и речи. М., 1976.

8. Нечаева О.А. Функционально-смысловые типы речи: Описание, повествование, рассуждение. Автореф. дис. на соиск. учен. степени доктора филол. наук. М., 1975.

9. Тамже.

10. Николаева Т.М. Лингвистика текста: Современное состояние и перспективы. - В кн.: Новое в зарубежной лингвистике; Лингвистика текста. М., 1978.

11. Звегинцев В.А. Предложение и его отношение к языку и речи. М., 1976.

12. Там же.

13. Там же.

14. Там же.

15. Изенберг Х. О предмете лингвистической теории текста. - В кн.: Новое в зарубежной лингвистике; Лингвистика текста. М., 1978.

16. Распопов И.П. Методология и методика лингвистических иссследований: Методы синхронного изучения языка. М., 1975.

17. Там же.

18. Там же. 
19. Там же.

20. Там же.

21. Колшанский Г.В. Соотношение субъективных и объективных факторов в языке. M., 1975.

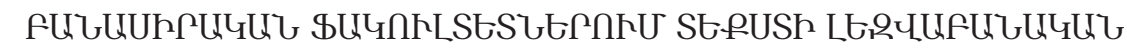

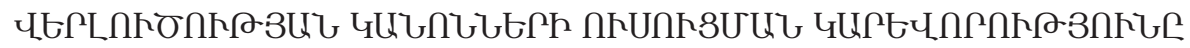

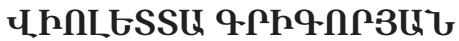

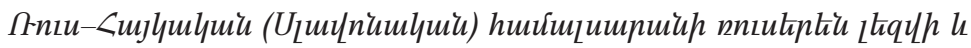

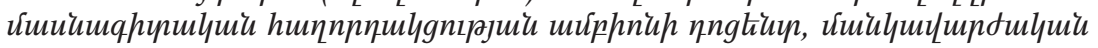

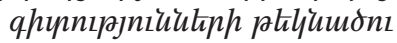

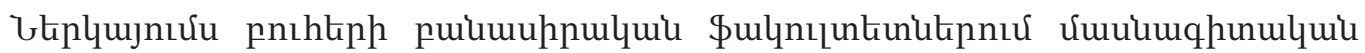

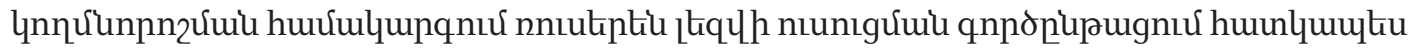

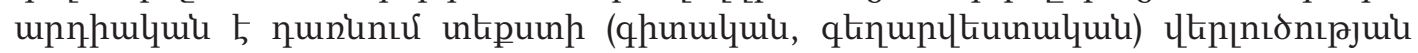

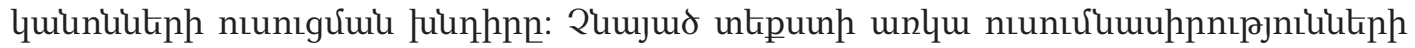

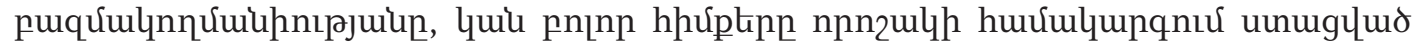

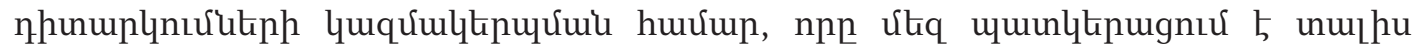

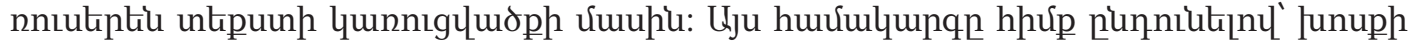

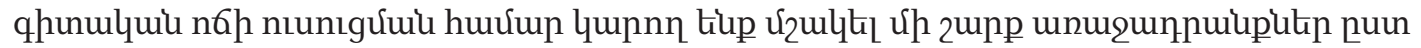

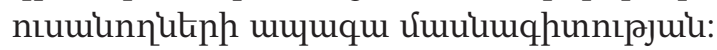

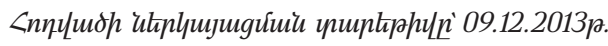

\title{
IMPORTANCE OF TEACHING THE RULES OF LINGUISTIC ANALYSIS \\ OF THE TEXT IN PHILOLOGICAL FACULTIES
}

\section{VIOLETTA GRIGORYAN}

Associate Professor of the Chair of the Russian Language and Professional Communication of Russian-Armenian (Slavonic) University, PhD in Pedagogy

Currently,the task of teaching the rules of the text (scientific, artistic)analysis is becoming particularly urgent in the philological faculties of the universities. Despite the multidimensionality of the existing studies of the text, there are many substantial reasonsfor the organization of observations in a certain system, which gives an idea of the structure of the Russian monologic text. Regarding this system as a base, we can develop a set of tasks for teaching the scientific style of speech of the students' future occupation. 